Revista Destaques Acadêmicos, Lajeado, v. 9, n. 4, 2017. ISSN 2176-3070 DOI: http://dx.doi.org/10.22410/issn.2176-3070.v9i4a2017.1559 www.univates.br/revistas

\title{
ANÁLISE DA EFICÁCIA DE UM PROGRAMA DE GESTÃO DE SEGURANÇA POR MEIO DE ANÁLISES PRELIMINAR DE RISCO
}

\author{
Rodrigo Grave ${ }^{1}$, Valdecir Sbardelini ${ }^{2}$
}

Resumo: A empresa FIRMA possui variadas atividades que apresentam possíveis riscos aos colaboradores no desempenho de suas funções. Este estudo tem teve como objetivo realizar análises preliminares de riscos em uma atividade desenvolvida na empresa FIRMA, sendo uma análise pré-implementação de um manual, no qual uma de suas aplicações é a segurança do trabalho, e uma nova avaliação após a verificação das medidas corretivas, considerando o novo grau de risco alcançado, proporcionando a comparação dos resultados das duas análises e verificando qual o grau de melhoria obtido. Sendo assim, os resultados atingidos foram de caráter satisfatório, apresentando uma redução de $46 \%$ em relação ás duas avaliações realizadas.

Palavras-chave: Análise. Risco. Medidas. Segurança.

\section{INTRODUÇÃO}

A empresa FIRMA possui variadas atividades que apresentam possíveis riscos de acidentes de trabalho. Conforme a NR-1 (DISPOSIÇÕES GERAIS, 1978), deverá ser observado e de caráter obrigatório em todas as normas regulamentadoras, independentemente do assunto:

As normas regulamentadoras - NR, relativas à segurança e medicina do trabalho, são de observância obrigatória pelas empresas privadas e públicas e pelos órgãos públicos de administração direta e indireta, bem como pelos órgãos dos poderes legislativos

1 Engenharia de Produção - Univates. Programa de Pós-Graduação Lato Sensu, Especialização em Segurança do Trabalho - Universidade do Vale do Taquari - Univates. Lajeado - RS, Brasil. E-mail: rodrigograve@hotmail.com

2 Mestrado em Engenharia - ULBRA. Professor - Programa de Pós-Graduação Lato Sensu, Especialização em Segurança do Trabalho - Universidade do Vale do Taquari - Univates. Lajeado - RS, Brasil. E-mail: valdecir.sbardelini@gmail.com 
e judiciários, que possuam empregados regidos pela Consolidação das Leis Trabalhistas - CLT.

Para o cumprimento da norma, a empresa optou por utilizar um manual que a multinacional para qual presta serviços disponibiliza com o programa denominado TOP, no qual um dos pilares de aplicabilidade é a segurança do trabalho.

Para este estudo executou-se uma análise preliminar dos riscos na atividade de separação e carregamento de carga no setor de Armazém, com o propósito de quantificar os existentes pré-implementação e os pósimplementação.

Após a execução da análise de risco, foi realizado um comparativo com dados coletados e apresentados à diretoria da empresa, a quem cabe avaliar a utilidade do programa disponibilizado pela multinacional.

Diante dessa situação, a utilização de um programa de análise de riscos que aplica medidas de segurança corretivas e preventivas, caso aplicadas, proporcionará uma redução do percentual de riscos de acidentes, gerando interesse dos diretores em apoiar a implementação do programa?

Este estudo teve como objetivo quantificar o percentual de redução de risco na utilização do programa TOP na atividade de separação e carregamento de cargas da empresa FIRMA. E como objetivos específicos a aplicação de uma análise preliminar de risco pré e pós a análise do programa, e uma comparação de resultados.

A realização deste estudo justifica-se pela importância de qualificar e quantificar os benefícios da implementação do manual TOP fornecido pela multinacional aos diretores da empresa, demostrando o percentual de redução de risco que o programa oferece e proporcionando uma condição mais segura para os trabalhadores.

\section{REVISÃO TEÓRICA}

\subsection{Conceito de Risco}

O conceito "risco" é utilizado como justificativa para alguma perda ou dano e como sinônimo de perigo. Os riscos podem apresentar-se de variadas fontes, tais como: fontes químicas, agentes físicos e mecânicos, agentes biológicos, ergonomia inadequada no desempenho do trabalho, tarefas repetitivas, ou ainda algum tipo de discriminação no local de trabalho (PORTO, 2000).

a) Metodologias de Análise de Riscos

De acordo com Calixto 2006, entende-se como gerenciamento de riscos a utilização de recursos - humanos, materiais e tecnológicos - de forma que 
evitem acidentes que possam causar injúrias à saúde dos trabalhadores ou impactos ambientais.

Pode-se entender que o gerenciamento de riscos se inicia no projeto, através da identificação de desvios no processo e condições inseguras, o que justifica a utilização de técnicas de análise de riscos nessas fases. Desse modo, o gerenciamento de riscos divide-se em algumas etapas, tais como: identificação dos riscos, planejamento e execução das ações e análise crítica dos riscos identificados (CALIXTO, 2006).

Para realizar esta identificação de perigos e riscos, necessita-se utilizar técnicas, tais como Análise Preliminar de Riscos e/ou o HAZOP (CARDELLA, 2011).

b) Análise Preliminar de Riscos (APR)

Análise Preliminar de Riscos - (APR) é uma técnica de identificação de riscos que consiste em avaliar e identificar acontecimentos perigosos, como também suas causas e consequências, e propor medidas de controle para esses eventos. Na maioria dos casos em que é aplicada, a APR é suficiente para estabelecer medidas para o controle de riscos. $\mathrm{O}$ objeto da APR pode ser um procedimento, operação ou atividade desenvolvida no ambiente analisado, enquanto seu foco são todos os eventos perigosos indesejáveis que podem ocorrer dentro dos parâmetros de ambiente analisados (CARDELLA, 2011).

De acordo com Tavares (2010), a APR é aquela aplicada durante a construção e desenvolvimento de um novo sistema, com a intenção de sinalizar os riscos que poderão estar presentes na fase operacional desse sistema. fases básicas:

Segundo Sherique (2011), a elaboração de uma APR consiste em algumas

- Avaliação dos problemas conhecidos;

- Estabelecimento de limites de atuação e delimitação do sistema;

- Determinação dos principais riscos: sinalização dos riscos com potencialidade de causar lesões e classificação dessas lesões;

- Avaliação dos meios de eliminação ou controle de riscos.

Conforme Amorim (2010), os resultados obtidos na Análise Preliminar de Riscos devem ser registrados em uma planilha, conforme Quadro 1 apresentado na metodologia, na qual, para cada etapa do processo, determinamse os perigos, as causas, métodos de detecção, efeitos, frequência, severidade e riscos, medidas corretivas e preventivas.

\section{METODOLOGIA}

O presente trabalho classifica-se como de natureza aplicada. Em relação aos seus objetivos, se trata de um estudo com característica descritiva, pois está dentro de uma abordagem quantitativa, na qual há levantamento de dados. 
Tratando-se de procedimentos de uma análise preliminar de risco, o artigo tem aspecto específico de um fenômeno e suas decorrências, portanto pode se classificar como um estudo de caso.

Em um primeiro momento, foram realizadas revisões bibliográficas sobre Análise Preliminar de Risco (APR), buscando compreender e aplicar o método.

Posteriormente, analisou-se a atividade de separação e carregamento de carga, pois essa apresenta variadas etapas a serem executadas, e realizou-se uma APR, sendo o modelo utilizado adaptado de Amorim (2010) e apresentado no Quadro 1, para verificação do grau de risco nessa situação. Após essa etapa, aplicou-se o manual fornecido pela multinacional, denominado TOP, que apresenta medidas de análise de melhoria de processo, no qual uma delas é a segurança do trabalho. Em seguida foi executada uma nova Análise Preliminar de Risco para verificação do novo grau de risco.

Por fim, realizou-se uma comparação entre os dois graus de risco e verificou-se o percentual de risco eliminado com a implementação no manual fornecido.

Quadro 1 - Planilha modelo de APR

\begin{tabular}{|c|c|c|c|c|c|c|c|c|c|c|}
\hline \multicolumn{11}{|c|}{ Planilha modelo de APR - Análise preliminar de riscos } \\
\hline \multirow[t]{2}{*}{ TÍTULO: } & & & & & & & & & & \\
\hline & \multirow[t]{2}{*}{ EVENTO } & \multirow[t]{2}{*}{ CAUSA } & \multicolumn{3}{|c|}{$\begin{array}{c}\text { PRÉ- } \\
\text { MEDIDAS } \\
\text { CORRETIVAS }\end{array}$} & \multirow{2}{*}{$\begin{array}{c}\text { MEDIDAS } \\
\text { CORRETIVAS }\end{array}$} & \multicolumn{3}{|c|}{$\begin{array}{c}\text { PÓS- } \\
\text { MEDIDAS } \\
\text { CORRETIVAS } \\
\end{array}$} & \multirow{2}{*}{$\begin{array}{c}\text { PERCENTUAL } \\
\text { REDUÇÃO DE } \\
\text { RISCO }\end{array}$} \\
\hline ATIVIDADE & & & $\mathrm{P}$ & S & $\mathrm{R}$ & & $\mathrm{P}$ & $\mathrm{S}$ & $\mathrm{R}$ & \\
\hline & & & & & & & & & & \\
\hline
\end{tabular}

Fonte: Adaptado Amorim (2010).

O Quadro 1 acima foi adaptado do modelo utilizado por Amorim (2010), onde $\mathrm{P}$ é probabilidade, $\mathrm{S}$ é severidade e $\mathrm{R}$ é risco, para apresentar comparativos dos riscos pré-medidas e pós-medidas, sendo possível a visualização das melhorias obtidas.

Cada atividade de acidente foi classificada em uma categoria de probabilidade $(\mathrm{P})$, a qual indica a frequência que cada atividade pode ocorrer, conforme apresentada no Quadro 2. 
Quadro 2 - Categorias de Probabilidade de Causa

\begin{tabular}{|c|l|l|l|}
\hline \multicolumn{5}{|c|}{ Categorias de Probabilidade da Causa } \\
\hline Categoria & \multicolumn{1}{|c|}{ Denominação } & \multicolumn{1}{c|}{ Probabilidade } & \multicolumn{1}{c|}{ Descrição } \\
\hline A & Extremamente rara & 1 a cada 100 anos & $\begin{array}{l}\text { Extremamente improvável de ocorrer } \\
\text { durante a vida útil }\end{array}$ \\
\hline B & Rara & 1 a cada 10 anos & Não deve ocorrer durante a vida útil \\
\hline C & Improvável & 1 a cada ano & Pouco provável que ocorra \\
\hline D & Provável & 1 a cada mês & Esperado ocorrer durante a vida útil \\
\hline E & Frequente & 1 a cada semana & Esperado ocorrer várias vezes \\
\hline
\end{tabular}

Fonte: Adaptado Amorim (2010).

As atividades foram classificadas em categorias de severidade (S), fornecendo uma indicação qualitativa de grau das consequências de cada uma, conforme mostrado no Quadro 3.

Quadro 3 - Categorias de Severidade

\begin{tabular}{|c|c|c|}
\hline & & Categorias de Severidade \\
\hline Categoria & Denominação & Descrição \\
\hline \multirow{3}{*}{$\mathrm{I}$} & \multirow{3}{*}{ Desprezível } & Sem danos ou danos insignificantes \\
\hline & & Sem lesões \\
\hline & & Pequena perda da produção \\
\hline \multirow{3}{*}{ II } & \multirow{3}{*}{ Leve } & Danos leves \\
\hline & & Lesões leves \\
\hline & & Perda parcial da produção \\
\hline \multirow{4}{*}{ III } & \multirow{4}{*}{ Crítica } & Danos severos \\
\hline & & Lesões graves \\
\hline & & Perda total da produção por curto tempo \\
\hline & & Exige medidas corretivas imediatas para não se tornar catastrófico \\
\hline \multirow{4}{*}{ IV } & \multirow{4}{*}{ Catastrófica } & Dano ambiental sem controle \\
\hline & & Morte \\
\hline & & Perda total de equipamentos \\
\hline & & Perda total da produção por longo tempo \\
\hline
\end{tabular}

Fonte: Adaptado Amorim (2010).

Após determinar-se a probabilidade e a severidade do risco, combinouse as duas e obteve-se a categoria de risco (R) através do Quadro 4. 
Quadro 4-Categoria de Risco

\begin{tabular}{|c|c|c|c|c|c|c|c|c|}
\hline \multicolumn{9}{|c|}{ Categoria de risco } \\
\hline & & \multicolumn{5}{|c|}{ PROBABILIDADE } & \multicolumn{2}{|r|}{ LEGENDA: RISCO } \\
\hline \multirow{5}{*}{ 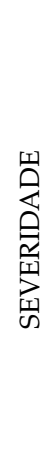 } & & A & B & C & $\mathrm{D}$ & $\mathrm{E}$ & 1 & Desprezível \\
\hline & I & 1 & 1 & 1 & 2 & 3 & 2 & Menor \\
\hline & II & 1 & 1 & 2 & 3 & 4 & 3 & Moderado \\
\hline & III & 1 & 2 & 3 & 4 & 5 & 4 & Sério \\
\hline & IV & 2 & 3 & 4 & 5 & 5 & 5 & Crítico \\
\hline
\end{tabular}

Fonte: Adaptado Amorim (2010).

\section{RESULTADOS}

A APR foi realizada em uma empresa situada no Vale do Taquari, a qual neste estudo, por motivo de sigilo, foi denominada de FIRMA. A empresa atende 52 municípios no entorno de sua sede e conta com uma estrutura de 120 funcionários. Sua principal atividade é vender e distribuir produtos para uma multinacional filiada.

Essa multinacional, como forma de auxiliar a empresa, aplica um sistema de gestão integrada denominado TOP (nome fictício), que busca analisar, melhorar os processos e aperfeiçoar a distribuição, aumentando assim os resultados da empresa. Seu objetivo é proporcionar o crescimento da empresa FIRMA. Uma das partes analisadas e considerada com maior importância é a segurança e, por isso, existem orientações de segurança para cada atividade que os colaboradores possam executar.

A partir disso, foi escolhido um conjunto de atividades necessárias para o carregamento de um caminhão e analisado o manual TOP, devido esta atividade ser considerada rotineira e crítica, verificando o percentual de risco diminuído quando aderidas as orientações descritas nele.

As atividades pertinentes à separação e carregamento de carga são descritas abaixo:

- Abastecimento do Picking: conforme a necessidade de reposição dos produtos que são fracionados na área de Picking, os operadores de 
empilhadeiras buscam os produtos no estoque e disponibilizam nessa área;

- Separação: os funcionários, trabalhando em duplas e orientados pela ordem de carga, realizam a separação dos produtos, acondicionandoos em paletes e utilizando paleteiras manuais para o transporte do produto da área do Picking até a área de conferência. Essa atividade é realizada simultaneamente por mais de uma dupla no mesmo local, juntamente com o reabastecimento do Picking realizado pelos operadores de empilhadeira;

- Conferência: após a separação, o produto e a ordem de carga são transferidos para área de conferência, onde o funcionário responsável pela atividade realiza a verificação dos produtos e da ordem de carga em todo o palete. Após a conferência, o funcionário autoriza a etapa de strechamento (atividade de enrolar o palete com plástico filme) do palete, liberando-o e realizando o acompanhamento para o carregamento;

- Carregamento: Após a liberação da conferência, o operador de empilhadeira retira o palete e o acomoda no caminhão. Caso ocorra de algum palete estar incompleto, um funcionário subirá no caminhão para ajustar a carga;

- Amarração e enlonamento do caminhão: Após a carga ser acomodada e ajustada no caminhão, um funcionário sobe no caminhão para realizar o ajuste das cantoneiras, enquanto outro, no solo, realiza a amarração das cordas. O enlonamento é realizado após a amarração por dois funcionários: aquele que está sobre o caminhão ajusta a lona e o que está no solo prende a lona no veículo utilizando presilhas elásticas.

Após a análise de todas as etapas que compõem a atividade descrita acima, realizou-se uma Análise Preliminar dos Riscos pertinentes a mesma. Constatou-se que o risco médio apresentado foi de 3,2. Depois da análise, consultou-se o manual TOP para verificação de melhorias na segurança para cada risco verificado.

Levando-se em consideração as possíveis melhorias avaliadas no manual, realizou-se uma nova análise de risco, a qual apresentou um risco médio de 1,8 .

Tanto a análise de pré-medidas corretiva, quanto às de pós, bem como as medidas corretivas, podem ser verificadas no Quadro 5, onde se apresenta detalhadamente a atividade avaliada, os eventos e as causas. 


\section{Quadro 5 - APR Análise Preliminar de Riscos}

\begin{tabular}{|c|c|c|c|c|c|c|c|c|c|c|c|}
\hline \multicolumn{12}{|c|}{ APR - Análise preliminar de riscos } \\
\hline TÍTULO: & \multicolumn{7}{|c|}{ Separação e carregamento de carga } & \multicolumn{3}{|c|}{ Data: } & \\
\hline \multirow[t]{2}{*}{ ATIVIDADE } & \multirow[t]{2}{*}{ EVENTO } & \multirow[t]{2}{*}{ CAUSA } & \multirow[t]{2}{*}{ ETAPA } & \multicolumn{3}{|c|}{$\begin{array}{c}\text { PRÉ- } \\
\text { MEDIDAS } \\
\text { CORRETIVAS }\end{array}$} & \multirow[t]{2}{*}{$\begin{array}{c}\text { MEDIDAS } \\
\text { CORRETIVAS }\end{array}$} & \multicolumn{3}{|c|}{\begin{tabular}{|c|} 
PÓS- \\
MEDIDAS \\
CORRETIVAS
\end{tabular}} & \multirow{2}{*}{$\begin{array}{l}\text { PERCENTUAL } \\
\text { REDUÇÃO DE } \\
\text { RISCO }\end{array}$} \\
\hline & & & & $\mathrm{P}$ & $\frac{A L 1}{S}$ & $\mathrm{R}$ & & $\begin{array}{cl}\mathrm{C} \\
\mathrm{P}\end{array}$ & $\frac{1 \mathrm{~L}}{\mathrm{~S}}$ & $\mathrm{R}$ & \\
\hline 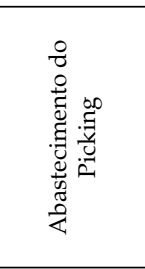 & $\begin{array}{l}\text { Atropelamen- } \\
\text { to por empi- } \\
\text { lhadeiras }\end{array}$ & $\begin{array}{c}\text { Impacto de } \\
\text { empilha- } \\
\text { deira }\end{array}$ & 1 & C & III & 3 & $\begin{array}{l}\text { Assegurar buzina de } \\
\text { ré em empilhadeiras e } \\
\text { veículos; Implantação } \\
\text { de sinalização } \\
\text { de trânsito de } \\
\text { empilhadeiras; } \\
\text { Avaliação de risco e } \\
\text { separação homem X } \\
\text { máquina. }\end{array}$ & A & III & 1 & $67 \%$ \\
\hline \multirow{6}{*}{ 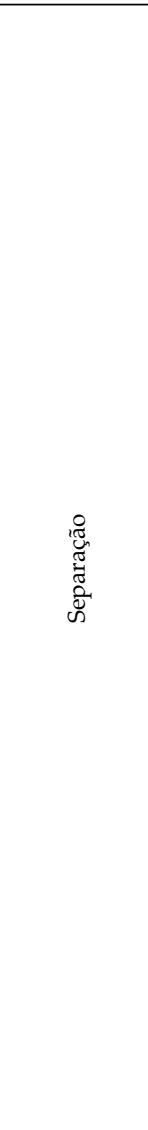 } & $\begin{array}{l}\text { Estouro de } \\
\text { garrafas }\end{array}$ & $\begin{array}{l}\text { Impacto } \\
\text { nos reci- } \\
\text { pientes } \\
\text { devido ao } \\
\text { manuseio } \\
\text { incorreto } \\
\end{array}$ & 2 & $\mathrm{D}$ & III & 4 & $\begin{array}{l}\text { Avaliação de risco } \\
\text { antes do início da } \\
\text { atividade; Utilização } \\
\text { de EPI's; Treinamento } \\
\text { para movimentação } \\
\text { manual de materiais. }\end{array}$ & $\mathrm{D}$ & II & 3 & $25 \%$ \\
\hline & $\begin{array}{l}\text { Prensamento } \\
\text { de membros }\end{array}$ & $\begin{array}{l}\text { Falta de } \\
\text { atenção no } \\
\text { manuseio } \\
\text { dos pro- } \\
\text { dutos }\end{array}$ & 3 & $\mathrm{C}$ & III & 3 & \begin{tabular}{|l|} 
Avaliação de risco \\
antes do início da \\
atividade; Utilização \\
de EPI's; Treinamento \\
para movimentação \\
manual de materiais. \\
\end{tabular} & B & III & 2 & $33 \%$ \\
\hline & $\begin{array}{l}\text { Tropeções, } \\
\text { escorregões e } \\
\text { quedas }\end{array}$ & $\begin{array}{l}\text { Piso ina- } \\
\text { dequado } \\
\text { e falta de } \\
\text { atenção }\end{array}$ & 4 & E & II & 4 & $\begin{array}{l}\text { Avaliação de risco; } \\
\text { Treinamento quanto } \\
\text { à prevenção de } \\
\text { tropeções e quedas; } \\
\text { Organização do } \\
\text { ambiente de trabalho. }\end{array}$ & C & II & 2 & $50 \%$ \\
\hline & $\begin{array}{l}\text { Queda de } \\
\text { materiais }\end{array}$ & $\begin{array}{l}\text { Materiais } \\
\text { acomo- } \\
\text { dados de } \\
\text { forma ina- } \\
\text { dequada }\end{array}$ & 5 & $\mathrm{D}$ & III & 4 & $\begin{array}{l}\text { Avaliação de risco } \\
\text { antes do início da } \\
\text { atividade; Utilização } \\
\text { de EPI's; Treinamento } \\
\text { para movimentação } \\
\text { manual de materiais. }\end{array}$ & $\mathrm{C}$ & II & 2 & $50 \%$ \\
\hline & $\begin{array}{l}\text { Atropelamen- } \\
\text { to por empi- } \\
\text { lhadeiras }\end{array}$ & $\begin{array}{l}\text { Impacto de } \\
\text { empilha- } \\
\text { deira }\end{array}$ & 6 & B & III & 2 & $\begin{array}{l}\text { Assegurar buzina de } \\
\text { ré em empilhadeiras e } \\
\text { veículos; Implantação } \\
\text { de sinalização } \\
\text { de trânsito de } \\
\text { empilhadeiras; } \\
\text { Avaliação de risco e } \\
\text { separação homem X } \\
\text { máquina. } \\
\end{array}$ & A & III & 1 & $50 \%$ \\
\hline & $\begin{array}{l}\text { Atropela- } \\
\text { mento por } \\
\text { paleteiras }\end{array}$ & $\begin{array}{l}\text { Impacto de } \\
\text { paleteira }\end{array}$ & 7 & $\mathrm{D}$ & III & 4 & $\begin{array}{l}\text { Avaliação de risco } \\
\text { antes do início da } \\
\text { atividade; Utilização } \\
\text { de EPI's; Treinamento } \\
\text { para movimentação } \\
\text { manual de materiais. }\end{array}$ & $C$ & II & 2 & $50 \%$ \\
\hline
\end{tabular}




\begin{tabular}{|c|c|c|c|c|c|c|c|c|c|c|c|}
\hline \multicolumn{12}{|c|}{ APR - Análise preliminar de riscos } \\
\hline TÍTULO: & \multicolumn{7}{|c|}{ Separação e carregamento de carga } & \multicolumn{3}{|c|}{ Data: } & \multirow{3}{*}{$\begin{array}{l}\text { PERCENTUAL } \\
\text { REDUÇÃO DE } \\
\text { RISCO }\end{array}$} \\
\hline \multirow[t]{2}{*}{ ATIVIDADE } & \multirow[t]{2}{*}{ EVENTO } & \multirow[t]{2}{*}{ CAUSA } & \multirow[t]{2}{*}{ ETAPA } & \multicolumn{3}{|c|}{$\begin{array}{c}\text { PRÉ- } \\
\text { MEDIDAS } \\
\text { CORRETIVAS }\end{array}$} & \multirow[t]{2}{*}{$\begin{array}{c}\text { MEDIDAS } \\
\text { CORRETIVAS }\end{array}$} & \multicolumn{3}{|c|}{$\begin{array}{c}\text { PÓS- } \\
\text { MEDIDAS } \\
\text { CORRETIVAS } \\
\end{array}$} & \\
\hline & & & & \begin{tabular}{|l}
$\mathrm{P}$ \\
\end{tabular} & $\mathrm{S}$ & $\mathrm{R}$ & & \begin{tabular}{|l}
$\mathrm{P}$ \\
\end{tabular} & $\mathrm{S}$ & $\mathrm{R}$ & \\
\hline \multirow{3}{*}{ 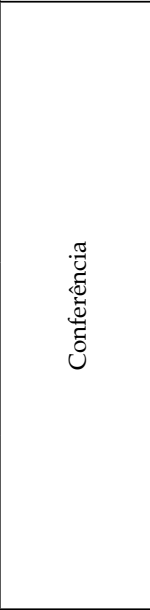 } & $\begin{array}{l}\text { Atropelamen- } \\
\text { to por empi- } \\
\text { lhadeiras }\end{array}$ & $\begin{array}{l}\text { Impacto de } \\
\text { empilha- } \\
\text { deira }\end{array}$ & 8 & C & III & 3 & $\begin{array}{l}\text { Assegurar buzina de } \\
\text { ré em empilhadeiras e } \\
\text { veículos; Implantação } \\
\text { de sinalização } \\
\text { de Trânsito de } \\
\text { empilhadeiras; } \\
\text { Avaliação de risco e } \\
\text { separação homem X } \\
\text { máquina. }\end{array}$ & A & III & 1 & $67 \%$ \\
\hline & $\begin{array}{l}\text { Estouro de } \\
\text { garrafas }\end{array}$ & $\begin{array}{l}\text { Impacto } \\
\text { nos reci- } \\
\text { pientes } \\
\text { devido a } \\
\text { manuseio } \\
\text { incorreto } \\
\end{array}$ & 9 & $\mathrm{D}$ & III & 4 & $\begin{array}{l}\text { Avaliação de risco } \\
\text { antes do início da } \\
\text { atividade; Utilização } \\
\text { de EPI's; Treinamento } \\
\text { para movimentação } \\
\text { manual de materiais. } \\
\end{array}$ & $\mathrm{D}$ & II & 3 & $25 \%$ \\
\hline & $\begin{array}{l}\text { Tropeções, } \\
\text { escorregões e } \\
\text { quedas. }\end{array}$ & $\begin{array}{l}\text { Piso ina- } \\
\text { dequado } \\
\text { e falta de } \\
\text { atenção }\end{array}$ & 10 & $\mathrm{E}$ & II & 4 & \begin{tabular}{|l} 
Avaliação de risco; \\
Treinamento quanto \\
à prevenção de \\
tropeções e quedas; \\
Organização do \\
ambiente de trabalho. \\
\end{tabular} & $\mathrm{C}$ & II & 2 & $50 \%$ \\
\hline \multirow{4}{*}{ 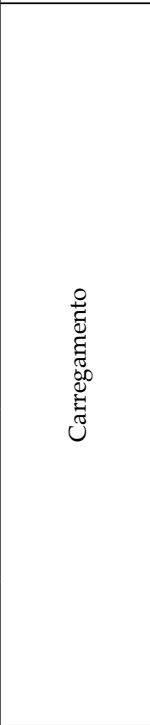 } & $\begin{array}{l}\text { Queda do } \\
\text { colaborador } \\
\text { do caminhão }\end{array}$ & $\begin{array}{l}\text { Perda de } \\
\text { equilíbrio; } \\
\text { Impacto } \\
\text { de outro } \\
\text { veículo }\end{array}$ & 11 & B & III & 2 & \begin{tabular}{|l|} 
Procedimento para \\
utilização de linha de \\
vida com talabarte \\
duplo e trava quedas; \\
Treinamento para uso \\
de linha de vida com \\
talabarte duplo e trava \\
quedas. \\
\end{tabular} & A & II & 1 & $50 \%$ \\
\hline & $\begin{array}{l}\text { Estouro de } \\
\text { garrafas }\end{array}$ & \begin{tabular}{|l|} 
Impacto \\
nos reci- \\
pientes \\
devido ao \\
manuseio \\
incorreto \\
\end{tabular} & 12 & $\mathrm{D}$ & III & 4 & \begin{tabular}{|l|} 
Avaliação de risco \\
antes do início da \\
atividade; Utilização \\
de EPI's; Treinamento \\
para movimentação \\
manual de materiais. \\
\end{tabular} & $\mathrm{D}$ & II & 3 & $25 \%$ \\
\hline & $\begin{array}{l}\text { Prensamento } \\
\text { de membros }\end{array}$ & $\begin{array}{l}\text { Falta de } \\
\text { atenção no } \\
\text { manuseio } \\
\text { dos pro- } \\
\text { dutos }\end{array}$ & 13 & $\mathrm{C}$ & III & 3 & \begin{tabular}{|l|} 
Avaliação de risco \\
antes do início da \\
atividade; Utilização \\
de EPI's; Treinamento \\
para movimentação \\
manual de materiais. \\
\end{tabular} & B & III & 2 & $33 \%$ \\
\hline & $\begin{array}{l}\text { Queda de } \\
\text { materiais no } \\
\text { colaborador }\end{array}$ & \begin{tabular}{|l|} 
Materiais \\
acomo- \\
dados de \\
forma ina- \\
dequada
\end{tabular} & 14 & $\mathrm{D}$ & III & 4 & $\begin{array}{l}\text { Avaliação de risco } \\
\text { antes do início da } \\
\text { atividade e utilização } \\
\text { de EPI's }\end{array}$ & $\mathrm{C}$ & II & 2 & $50 \%$ \\
\hline 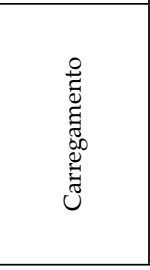 & $\begin{array}{l}\text { Atropela- } \\
\text { mento por } \\
\text { máquina ou } \\
\text { veículos }\end{array}$ & $\begin{array}{l}\text { Impacto de } \\
\text { empilha- } \\
\text { deira ou } \\
\text { caminhão }\end{array}$ & 15 & B & III & 2 & \begin{tabular}{|l|} 
Assegurar buzina de \\
ré em empilhadeiras e \\
veículos; \\
Implantação de \\
sinalização de Trânsito \\
de empilhadeiras; \\
Avaliação de risco e \\
separação homem X \\
máquina. \\
\end{tabular} & A & III & 1 & $50 \%$ \\
\hline
\end{tabular}




\begin{tabular}{|c|c|c|c|c|c|c|c|c|c|c|c|}
\hline \multicolumn{12}{|c|}{ APR - Análise preliminar de riscos } \\
\hline TÍTULO: & \multicolumn{7}{|c|}{ Separação e carregamento de carga } & \multicolumn{3}{|c|}{ Data: } & \multirow{3}{*}{$\begin{array}{l}\text { PERCENTUAL } \\
\text { REDUÇÃO DE } \\
\text { RISCO }\end{array}$} \\
\hline \multirow[t]{2}{*}{ ATIVIDADE } & \multirow[t]{2}{*}{ EVENTO } & \multirow[t]{2}{*}{ CAUSA } & \multirow[t]{2}{*}{ ETAPA } & \multicolumn{3}{|c|}{\begin{tabular}{|c|} 
PRÉ- \\
MEDIDAS \\
CORRETIVAS
\end{tabular}} & \multirow[t]{2}{*}{$\begin{array}{c}\text { MEDIDAS } \\
\text { CORRETIVAS }\end{array}$} & \multicolumn{3}{|c|}{$\begin{array}{c}\text { PÓS- } \\
\text { MEDIDAS } \\
\text { CORRETIVAS } \\
\end{array}$} & \\
\hline & & & & $\begin{array}{cl}\mathrm{Cl} \\
\mathrm{P}\end{array}$ & $\mathrm{S}$ & $\frac{\mathrm{N} M U}{\mathrm{R}}$ & & $\frac{\mathrm{COI}}{\mathrm{P}}$ & KEII & $\frac{V A S}{R}$ & \\
\hline \multirow{4}{*}{ 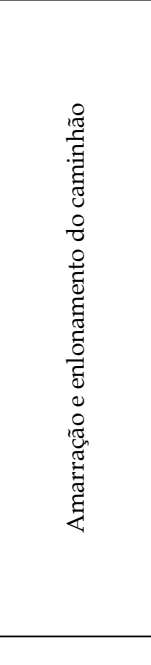 } & $\begin{array}{l}\text { Queda do } \\
\text { colaborador } \\
\text { do caminhão }\end{array}$ & $\begin{array}{l}\text { Perda de } \\
\text { equilíbrio; } \\
\text { Impacto } \\
\text { de outro } \\
\text { veículo }\end{array}$ & 16 & B & III & 2 & \begin{tabular}{|l|} 
Procedimento para \\
utilização de linha de \\
vida com talabarte \\
duplo e trava quedas; \\
Treinamento para uso \\
de linha de vida com \\
talabarte duplo e trava \\
quedas. \\
\end{tabular} & A & II & 1 & $50 \%$ \\
\hline & \begin{tabular}{|l|} 
Queda de \\
materiais no \\
colaborador \\
que está \\
auxiliando
\end{tabular} & \begin{tabular}{|l|} 
Materiais \\
acomo- \\
dados de \\
forma ina- \\
dequada
\end{tabular} & 17 & D & III & 4 & $\begin{array}{l}\text { Avaliação de risco } \\
\text { antes do início da } \\
\text { atividade; Utilização } \\
\text { de EPI's. }\end{array}$ & C & II & 2 & $50 \%$ \\
\hline & $\begin{array}{l}\text { Atropela- } \\
\text { mento por } \\
\text { máquina ou } \\
\text { veículos }\end{array}$ & $\begin{array}{l}\text { Impacto de } \\
\text { empilha- } \\
\text { deira ou } \\
\text { caminhão }\end{array}$ & 18 & B & III & 2 & $\begin{array}{l}\text { Assegurar buzina de } \\
\text { ré em empilhadeiras e } \\
\text { veículos; } \\
\text { Implantação de } \\
\text { sinalização de trânsito } \\
\text { de empilhadeiras; } \\
\text { Avaliação de risco e } \\
\text { separação homem X } \\
\text { máquina. } \\
\end{array}$ & A & III & 1 & $50 \%$ \\
\hline & MÉDIA & & & & & 3,2 & & & & 1,8 & $46 \%$ \\
\hline
\end{tabular}

Fonte: Do autor (2017).

Após a realização da APR montou-se um gráfico, (Gráfico 1) onde é possível visualizar a redução de risco em cada atividade citada acima.

\section{Gráfico 1 - APR Análise Preliminar de Riscos}

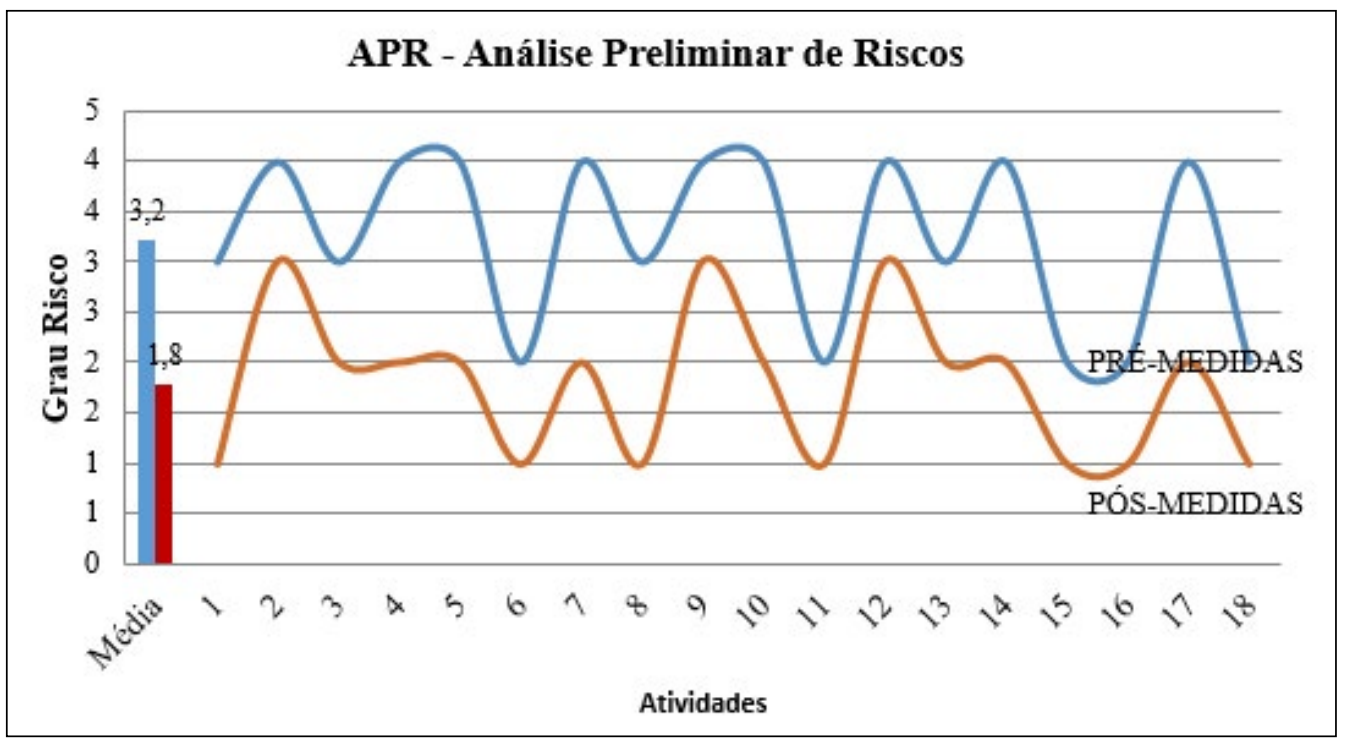

Fonte: Do autor (2017). 


\section{CONSIDERAÇÕES FINAIS}

Conclui-se que o presente trabalho atingiu o objetivo geral determinado, pois com a APR - Análise Preliminar de Risco - foi possível determinar que a implementação do manual TOP gerasse uma diminuição no risco em média de $46 \%$.

Em relação aos objetivos específicos, todos foram atingidos. Entre estes estava a realização de uma análise pré-medidas corretivas, a qual constatou um risco médio de 3,2, número que se enquadra de moderado a sério de acordo com o Quadro 4 apresentado na metodologia.

Também foi realizada uma segunda análise pós-medidas corretivas, com a qual se pode verificar que o risco médio foi de 1,8, enquadrando-se de desprezível a menor de acordo com o Quadro 4 apresentado na metodologia.

Desta forma, os resultados obtidos apresentados aos diretores foram recebidos de forma satisfatória, autorizando a implementação e execução do manual TOP na empresa.

Como sugestão de continuidade de aplicação deste estudo, sugere-se uma análise de risco após a implementação e execução do manual TOP para comprovação dos resultados obtidos.

\section{REFERÊNCIAS}

AMORIM, E. L. C. de. Ferramentas de Análise de Risco. Apostila do curso de Engenharia Ambiental da Universidade Federal de Alagoas, CTEC, Alagoas, 2010.

CALIXTO, Eduardo. Uma metodologia para gerenciamento de risco em empreendimentos: Um estudo de caso na Indústria de petróleo. In: XXVI ENEGEP. Fortaleza, 2006.

CARDELLA, Benedito. Segurança no trabalho e prevenção de acidentes: uma abordagem holística. São Paulo: Atlas, 2011.

NORMA REGULAMENTADORA - NR 1 - Disposições Gerais, Ministério do Trabalho e Emprego. Portaria n 6,09 mar. 1983.

PORTO, Marcelo Firpo de Souza. Análise de riscos nos locais de trabalho: conhecer para transformar. São Paulo: INST, 2010.

SHERIQUE, Jaques. Aprenda como fazer. 7. ed. São Paulo: LTr, 2011.

TAVARES, J. C. Noções de Prevenção e controle de perdas em Segurança do Trabalho. São Paulo: SENAC, 2010. 